\title{
Appendix 6: Pen Portraits
}

Aleen

Was one of the younger participants in the research and underwent one cycle of egg freezing when she was 33, retrieving 11 eggs, and completed a second cycle when she was 35 , freezing a further 13 . Aleen was 35 at the time of the interview, single and had recently lost her mother to cancer whom she had been helping care for since she was 29. As a result, Aleen had not pursued a longterm or significant relationship in this time and wanted more time to recover from her mother's death before throwing herself into dating. She explained how her mother had undergone IVF to conceive her and how this made her concerned about her own fertility as she had also been diagnosed with PCOS. Aleen told me how her mother was very supportive of her freezing her eggs and how she was able to use the inheritance she received from her mother to pay for the procedure. Aleen didn't want to use donor sperm to conceive and was hopeful she would find a partner.

\section{Amber}

Was a British woman who underwent one round of egg freezing, banking 24 eggs when she was 36 after the end of a 15-year-long relationship which she had hoped would lead to motherhood. However, her partner was unwilling to commit to parenthood which saw the relationship break down. Amber described wanting to freeze her eggs so she may be able to pursue motherhood as part of a new relationship in the future but also described having fears about her fertility due to a history of cancer in the family as well as the fact that she had polycystic ovaries. Amber was 40 when I met her and had recently decided to attempt a cycle of fresh IVF using donor sperm; if this was not successful she was going to TTC using her frozen eggs.

\section{Anne}

Was an American woman living in Chicago where she underwent one cycle of egg freezing was she was 36 years old, banking 18 eggs for potential future use. She heard about egg freezing through an acquaintance and decided to undergo the procedure as she was single but wanted to have a child in the future. Ann experienced OHSS and had gained $10 \mathrm{lbs}$ in a four-day period after retrieval and had to have a build-up of water surgically drained from her body. She described the experience of such side effects as shocking and not something she had anticipated. She hoped to find a partner and pursue motherhood naturally 
but hoped that a future partner would be thankful for the forward thinking she displayed by freezing her eggs.

\section{Catrine}

Was a Norwegian woman who underwent one round of egg freezing and banked 19 eggs when she was 34. She travelled to Spain to have the procedure due to restrictions on the technology in her home country. Catrine was one of the few women who froze eggs whilst in a serious relationship. She froze her eggs shortly before she and her partner decided to TTC. She did not discuss her decision to freeze eggs with her partner in great depth and instead went about the process independently. She sought to freeze her eggs as although she was in a relationship she was concerned about its longevity.

\section{Charlotte}

Was an American woman living in Chicago who underwent one round of egg freezing when she was 42 and was able to bank 15 eggs. Charlotte described undergoing egg freezing after the sudden breakdown of a relationship she thought would lead to motherhood; however she initially struggled to find a clinic which would perform the procedure due to her age and because she only had one healthy ovary following a burst ovarian cyst when she was younger. Charlotte did not want to pursue SMC via sperm donation and instead hoped to meet a partner.

\section{Claire}

Was a New Zealander living in the United Kingdom who underwent one round of egg freezing when she was 39, banking five eggs. She wanted to undergo a second cycle of egg freezing but was advised against doing so as she would be unlikely to produce very many eggs. Claire was 41 at the time of the interview and explained that she had wanted to become a mother since she was 32 but had only been in short-term relationships which had never become serious enough to consider parenthood. She had recently come to the conclusion that if she wanted to have children she was likely going to need to pursue motherhood alone and was considering SMC via sperm donation; however the prospect of doing so was something she was very much struggling with. She explained how she was considering moving back to New Zealand to live closer to her family whose support she believed she would need to become a mother alone and because she did not believe she could raise a child alone whilst living in London.

\section{Claudia}

Was a New Zealander living in London who had undergone two rounds of egg freezing when she was 36 and 37, banking 13 eggs for future use. At the time of the interview Claudia was 41. Claudia described wanting to become a mother since her mid-20s but had experienced multiple failed relationships. In one of her previous relationships she had attempted motherhood with her frozen eggs from which four embryos were created; two were implanted but did not result in a pregnancy. The relationship she was in then turned abusive and she left her partner who insisted that the remaining two embryos were destroyed. At 
the time of the interview Claudia was in a new relationship with a man 10 years her junior who was not yet being ready for fatherhood. He offered to pay for her to freeze more eggs but due to her age this was not a viable prospect. In the end they travelled to the Czech Republic to freeze embryos as her partner wanted to wait before TTC. Claudia later suggested trying a fresh round of IVF but her partner said he wanted to wait six months. During this time Claudia fell pregnant naturally; she described her partner being shocked and upset noting that they had agreed to TTC in six months anyway to which he responded that he had already decided that at the end of that six-month period he was going to suggest waiting another six months.

\section{Effsie}

Was a British woman living in London who had undergone one round of egg freezing when she was 38, storing 10 eggs. Effsie described undergoing the procedure due to the lack of a partner and because she wanted to keep the option of motherhood open in the future. She described difficulties in reconciling the use of hormone drugs as she otherwise tried to avoid toxins and medications. She explained she had seen friends of hers undergo five rounds of IVF and believed this was not something she was prepared to do in order to have a child. She said she would like to consider SMC but did not believe she had the extended support network she would need to pursue such a route to motherhood.

\section{Ellen}

Was an Australian woman living in the United Kingdom who had undergone three rounds of egg freezing when she was 40 and 41, banking 34 eggs for future use. She described freezing her eggs due to the lack of a suitable partner. Shortly before the interview took place, and when Ellen was 45, a relationship she was hoping may lead to motherhood had broken down and she was now unsure if she would find a partner with whom to pursue motherhood. She did not want to become a SMC and wanted to raise a child as part of a two-parent family in a stable home.

\section{Emily}

Was a British woman who underwent three cycles of egg freezing between the ages of 37 and 39, banking a total of 30 eggs. Emily was divorced and in a new relationship but explained how at the time of freezing her eggs that relationship was too new to consider pursing parenthood or freezing embryos, but equally she did not want to do nothing to protect her chance of future motherhood. Around five years after freezing her eggs she and her partner were still together and decided to TTC. After trying naturally for six months they went and used some of her frozen eggs to have a child. Ten of Emily's eggs were thawed, nine survived the thaw, eight were successfully fertilised and three were deemed good enough quality to try and use to conceive. Two embryos were transferred during fertility treatment and one remaining embryo was frozen and stored with her remaining fresh eggs. Emily gave birth to a daughter following ICSI with her 
frozen eggs and she and her partner were going to try for a second child using some more of her frozen eggs in the near future.

Hayley

Was a British woman living in London who had undergone one round of egg freezing when she was 36 , freezing nine eggs for future use. Hayley described wanting to become a mother since her early 30 s but had trouble finding a partner with whom to pursue motherhood. She froze her eggs when she was 36 after hearing that after 35 the success rates with frozen eggs may be lower. She knew several people working in the fertility industry who she was able to talk to about the technology. With emotional and financial support from her mother Hayley froze her eggs and hoped she would find a partner with whom to pursue motherhood in the future.

\section{Helena}

Was a German woman living in the United Kingdom who had undergone one round of egg freezing recently at the age of 37 . She described undergoing the procedure due to the lack of a suitable partner but also explained how a recent healthcare made her evaluate and think more about her fertility. She had not been in a serious relationship in her 30 s and wanted to meet the right partner with whom to pursue parenthood. She hoped egg freezing would allow her more time to find such a partner and take the pressure off the search. Helena did not want to pursue SMC via sperm donation and wanted to become a mother by the time she was 45 and in a committed relationship.

\section{Holly}

Was a British woman who attempted four cycles of egg freezing when she was 37 and 38; however, two of these cycles had to be cancelled as she was not responding sufficiently to the stimulation protocol. In the end she banked 10 eggs for future use. Holly underwent egg freezing after the breakdown of a 13year relationship and after experiencing another, new relationship breakdown and wanted to keep the possibility of motherhood open in the future. At the time of the interview Holly was 38 and unlike some of the other participants did not describe a strong desire to pursue motherhood but it was something she thought she might like to pursue in the future. She was considering pursuing motherhood with her ex-partner who she was with for 13 years as well as considering using donor sperm.

\section{Jen}

Was an American woman who underwent one round of egg freezing when she was 37, banking 18 eggs for future use. At the time of the interview she was about to turn 40 and explained how she had wanted to have children for 10 years, but had not yet been in a relationship where motherhood was an option. She explained that she separated from her husband in her early 30 s as he would not commit to having children and froze her eggs shortly after coming out of a relationship which she had hoped would lead to parenthood. Jen explained that she had since got married and started TTC right away as she was 38 and knew it 
may be difficult to conceive. After TTC for six months they attempted IUI and Jen fell pregnant but miscarried at nine weeks. Soon after this the couple decided to use her frozen eggs to try and have a baby, however tragically all her eggs were accidentally thawed in transit between her old and new fertility clinic destroying them. At the time of the interview she explained that they were going to TTC using her fresh eggs and then if unsuccessful would try to adopt. She was certain she would become a mother.

\section{Johanna}

Was a British woman living in London who underwent one round of egg freezing when she was 41 , banking 12 eggs. She described being aware of egg freezing in her 30s but said she did not believe the technology was sufficiently successful to warrant undergoing the procedure when she was younger and had hoped that she would meet someone and pursue motherhood naturally. She had considered freezing embryos but wanted the possibility of pursuing shared genetic parenthood with a partner in the future. She was hopeful she would find such a partner but explained it was difficult to find single men willing to commit to long-term relationships and fatherhood in London.

\section{Kanta}

Was a British woman whose family were originally from South Asia. She attempted two cycles of egg freezing, the first of which produced three eggs for freezing however the second cycle was cancelled as she was not responding to the stimulation drugs enough to warrant continuing with the procedure. She froze her eggs when she was 37 as she did not yet have a partner and was told she had low fertility. After freezing her eggs, she underwent fresh IVF with donor sperm but miscarried and was later told she was peri-menopausal. At the time of the interview she was 39 and was now considering egg and sperm donation but she would still like to have a child with a partner. She had little faith in her three frozen eggs.

\section{Katie}

Was an American woman who underwent one round of egg freezing when she was 37, banking 26 eggs for future use. Unlike some of the participants Katie was more ambivalent about motherhood and wasn't sure if it was something she definitely wanted to pursue, however she thought she may feel differently should she meet the 'right' partner so froze her eggs to keep the possibility of shared genetic parenting open.

\section{Lacey}

Was a British woman who attempted three rounds of egg freezing when she was 37 , whilst her third cycle was unsuccessful and had to be terminated before retrieval she was able to bank 19 eggs for future use. Lacey froze her eggs as she was not in a relationship and wanted the possibility of pursuing motherhood with a partner. At the time of the interview she was 40 years old and had recently relocated to live closer to her family outside of London where she was hoping to TTC via a fresh round of IVF using donated sperm, she was also 
considering using PGD to help boost the chance of a live birth with her fresh eggs. If she was unable to conceive via fresh IVF she was hopeful that her frozen eggs would provide her with a child.

\section{Leona}

Was a British woman living in London who underwent one round of egg freezing when she was 36 after being told when she was 34 that she would be likely to experience premature menopause like her mother and grandmother before her. Hopeful that she would meet a partner and pursue motherhood naturally Leona did not turn to egg freezing until a few years later. She was only able to bank four eggs and her clinician advised her that it would not be advisable to attempt another round of freezing. Shortly after freezing her eggs she decided to pursue SMC via sperm donation as she had a strong desire to become a mother. After five attempts at IUI she conceived her daughter. Leona described how she had spent much of her 20s and 30s single or in short-term relationships and really wanted to find a partner but described how the pressure to enter in to a long-term relationship disappeared once she had her daughter. She was hopeful however that she may have a long-term relationship in the future but was for the time being focusing on her daughter.

\section{Lindie}

Was 32 at the time of freezing her eggs and was the youngest woman in the sample (at the time of egg freezing). She underwent the procedure after the end of a long-term relationship and to allow herself time to recover from that relationship before returning to dating more seriously. She underwent one round of egg freezing and banked 12 eggs for future use. At the time of the interview Lindie was 34 and in a new relationship which she hoped would lead to motherhood. Lindie was referred to the research by Sofia who she described as offering her much support throughout the egg freezing process.

\section{Livvy}

Was a British woman now living in France who had attempted to freeze her eggs when she was 35 as the man who she was currently in a relationship with did not yet want to have children and she was concerned about the longevity of the relationship as well as her fertility. She hoped that by freezing her eggs she could keep open the possibility of motherhood should the relationship fail. Livvy attempted one cycle of egg freezing which was cancelled after she did not respond to the hormone medication. She was later told that she had gone into premature menopause and that it was unlikely that she would be able to conceive. However, a month after the failed cycle of egg freezing she found out she was pregnant. Her partner was unsure about becoming a father, but they remained together, and she described how he has since said he wishes they could have more children.

\section{Mabel}

Was a 41-year-old American woman who underwent two rounds of egg freezing when she was 39 and 40 after her on-again-off-again relationship broke 
down. She was able to freeze 25 eggs for potential future use. She described wanting to freeze her eggs to take the pressure off the search for a partner. At the time of the interview Mabel had reconciled with her partner and they had got married and, after trying to conceive naturally, turned to her frozen eggs to conceive, which had resulted in an ongoing pregnancy. Mabel gave birth to nonidentical twins from her frozen eggs and said she would like to attempt pregnancy in the future with her remaining frozen embryo.

\section{Mary}

Was the oldest participant in this research, she underwent one round of egg freezing when she was 44 and was 49 at the time of the interview. Mary was divorced and had been married for several years during her 20s and 30s; however, she had not attempted childbearing as she and her partner were enjoying successful careers in publishing. Her marriage broke down when she was 39; however, Mary described not being worried about her fertility at this time, an issue she later came to regret. She wanted to freeze her eggs to keep open the possibility with a partner in the future. She was informed by her clinic that the procedure may not be successful in providing her a live birth, but she wished to pursue the technology anyway. At the time of the interview she was in a relationship with a partner who lived overseas but who said he was happy to try and conceive a child which she would mostly raise alone. Mary was referred to the study by Livvy.

\section{Melanie}

Was a mixed-race American woman who underwent once cycle of egg freezing after the end of a three-year relationship with a partner who was reluctant to pursue fatherhood. She was 36 at the time of freezing her eggs. Melanie wanted to have a child with a partner in the future and was currently in a new relationship but wanted to allow that relationship time to develop before considering TTC. She wanted to have become a mother by the time she was 42 and suggested she may consider SMC via sperm donation at 38 if her current relationship failed. She commented how the process of freezing eggs was very emotionally challenging.

\section{Olivia}

Was a 39-year-old British woman living in London who underwent two rounds of egg freezing when she was 36, storing 12 eggs for future use. She underwent the procedure as she did not have a partner and whilst being unsure about whether she wanted to become a mother, she wanted to keep the option open for the future. At the time of the interview she was engaged and was talking to her partner about TTC naturally in a few months' time. However, she disclosed that due to his Middle-Eastern background he was not keen on using IVF to conceive.

\section{Patricia}

Was a British woman living in London and had undergone one round of egg freezing when she was 37, storing 29 eggs for potential future use. She had 
considered undergoing the procedure when she was younger but had hoped that she would meet a partner and pursue motherhood naturally. She froze her eggs due to the lack of a suitable partner and because one of her fallopian tubes was blocked which could make it harder for her to conceive. At the time of the interview she was 41 and described wanting to have a child since she was 31 but had been in relationships with men unwilling to commit to fatherhood. She had asked a male friend to donate sperm to her; however during this process she fell pregnant with her partner and was in the very early stages of pregnancy. She hoped this pregnancy would result in a child and said she would not have wanted to be attempting motherhood beyond the age of 46 .

\section{Preeti}

Was a British woman whose family were originally from Bangladesh. She froze 14 eggs following two cycles of egg freezing when she was 35 and 36. She underwent the procedure after finding out she had a low ovarian reserve for a woman of her age. She hoped to find a partner in the future to have a child and found it insensitive when other people told her she should simply have a child on her own. She explained that her family would not support her if she became a single mother and said she could lose contact with them entirely if she pursued SMC. Preeti visited a counsellor which helped her realise that she would rather have a partner and no genetically related children than have a child on her own. She was hopeful she would meet a partner in the near future and did not ideally want to be attempting motherhood beyond her early 40 s.

\section{Rachel}

Was a British woman living in London, she underwent egg freezing twice through a 'freeze and share' programme as she would not have otherwise been able to afford the procedure. At the end of two cycles she had eight eggs banked for herself. She wanted to do a third cycle but her AMH was too low and as such she was no longer a suitable candidate. She froze her eggs when she was 33 as she was in a relationship with a man 20 years her senior who had an older child from a previous relationship and did not want more children. She had hoped he may change his mind about having children and ultimately left the relationship to find a partner who would commit to having a child. She was interviewed a year after freezing her eggs and was now considering freezing embryos and was open to SMC via sperm donation.

\section{Rae}

Was an American woman living in New York who had undergone two rounds of egg freezing when she was 39, storing 62 eggs. She had turned to egg freezing after a series of relationships had ended which she had hoped would lead to motherhood. She wanted more time to find a partner and become ready in that relationship prior to pursuing parenthood. She did not want to have a child alone, believing she would not be able to raise one on her salary alone in New York but equally didn't want to relocate otherwise she would lose her support network. She experienced some significant side effects from the procedure including weight gain and bloating and 'kissing ovaries'. 
Shu

Was a 39-year-old British-born Chinese woman living in London who was about to start the first of what she expected would be two rounds of egg freezing. Shu described feeling 'broody' about having a child since she was 35 but explained that her marriage broke down when she was 37 . She considered freezing her eggs when she was 37 but said she did not think the technology was sufficiently viable at that time but had recently revised her opinion. She explained that if she did not find a partner with whom to have a child she would consider using sperm from a known donor such as a friend or co-parenting with her ex-husband with whom she still had a good relationship.

\section{Sofia}

Was an Argentinian woman living in the United Kingdom, she underwent three rounds of egg freezing when she was 35 and 36 and was able to bank 10 eggs. She was single at the time of freezing her eggs and wanted to have a child with a partner in the future however she also had severe (grade 4) endometriosis and had to have surgery which left her with a reduced ovarian reserve. At the time of the interview she was 39 and after getting married a few years earlier had started TTC. She suffered one miscarriage and had attempted four or five fresh rounds of IVF with her husband all which had failed. She attempted conception using her frozen eggs which produced three embryos, but these also did not produce a live birth. She was about to begin the process of IVF using an American egg donor which she selected to have more information about the donor profile. She estimated she had spent over $£ 100,000$ on fertility treatments. 